\title{
Lenticel infection in Fraxinus excelsior shoots in the context of ash dieback
}

\author{
Miguel Nemesio-Gorriz ${ }^{(1)}$, \\ Brian McGuinness ${ }^{(2)}$, \\ Jim Grant ${ }^{(3)}$, \\ Luke Dowd ${ }^{(4)}$, \\ Gerry C Douglas (1)
}

\begin{abstract}
Common ash (Faxinus excelsior L.) in Europe is declining on a continental scale due to the action of Hymenoscyphus fraxineus, an invasive forest pathogen that causes ash dieback disease leading to the collapse and eventual death of ash trees through shoot infection in the crown and through stem collar infection. This study confirms for the first time lenticels as entry points for pathogens to enter shoot bark. Results show the impact of lenticel infection at a very early stage of invasion by $H$. fraxineus in a $F$. excelsior provenance trial and its correlation values with other factors such as shoot dieback, canker-like lesions and bud burst. No significant provenance effects were observed for incidence of shoot dieback, lenticel necrosis or canker-like lesions on shoots, but provenance effects were significant for bud burst phenology. The strongest correlation was observed between lenticel necrosis and canker-like lesions on the lenticels of shoots. Boheremia spp. were most frequently isolated from necrotic ash lenticels and confirmed by ITS sequencing, but also species of $\mathrm{Di}$ aporthe, Epicoccum, Aspergillus, Neonectria, Didymella and Hymenoscyphus fraxineus. Finally, lenticel density was similar in sets of ash genotypes that were characterized as having a high and low susceptibility to ash dieback.
\end{abstract}

\section{Keywords: Ash Dieback, Lenticel, ADB, Phenology}

\section{Introduction}

The necrotrophic ascomycete Hymenoscy phus fraxineus (Baral et al. 2014) is a major invasive forest pathogen in Europe and is the causal agent of ash dieback disease in European common ash (Fraxinus excelsior L.); narrow-leaved ash ( $F$. angustifolia) is also susceptible (Kirisits et al. 2010, Hauptman et al. 2016, Nielsen et al. 2017a). The pathogen is likely to have come from East ern Asia (McMullan et al. 2018, Sønstebø et al. 2017). Ash dieback disease was observed for the first time in the early 90 s in Poland but it was not until the 2000 s that the pathogen was isolated (Kowalski 2001) and described (Kowalski 2006) as the causal agent of ash dieback. $H$. fraxineus is a heterothallic organism. The sexual phase takes place on dead ash petioles and rachises in the litter. Spores are dispersed by the wind and infect host leaves during summer (Gross et al. 2014), but also in late spring (Chandelier et al. 2014) and possibly in autumn. After an initial infection in the leaflets the organism spreads through the leaf rachis and from the petiole it invades the shoot inducing necrotic lesions that eventually encircle shoots, causing shoot dieback (Gross et al. 2014). As disease pressure increases, crown dieback intensifies leading to the decay and eventual collapse of the host (Bakys et al. 2013, Schumacher et al. 2010, Skovsgaard et al. 2010). To date, ash dieback disease has degraded ash woodlands and ecosystems throughout eastern, central and northern Europe overlapping almost completely with the natural distribution of $F$. excelsior, which is a highly susceptible host for this pathogen (McKinney et al. 2014). In addition to the symptoms of shoot dieback in the crown, stem and collar infections have also been reported (Kowalski \& Bartnik 2010, Enderle et al. 2013, 2017a, Muñoz et al. 2016). In the

$\square$ (1) Forestry Development Department, Teagasc, Dublin (Republic of Ireland); (2) Horticulture Development Department, Teagasc, Dublin (Republic of Ireland); (3) Research Operations Group, Teagasc, Dublin (Republic of Ireland); (4) Forestry Faculty, University College Dublin, Dublin (Republic of Ireland)

@ Miguel Nemesio-Gorriz (miguel.nemesiogorriz@teagasc.ie)

Received: Jun 15, 2018 - Accepted: Jan 12, 2019

Citation: Nemesio-Gorriz M, McGuinness B, Grant J, Dowd L, Douglas GC (2019). Lenticel infection in Fraxinus excelsior shoots in the context of ash dieback. iForest 12: 160-165. doi: 10.3832/ifor2897-012 [online 2019-03-04]

case of collar infections it has been suggested that they occur through the stem lenticels at the base of the tree (Husson et al. 2012, Chandelier et al. 2016). Even though direct infection of bark in young shoots and leaf rachis can be induced by artificial inoculation with mycelium following wounding (Kräutler et al. 2015, Schwanda \& Kirisits 2016), there are no reports about infection mechanisms allowing $\mathrm{H}$. fraxineus to naturally infect the bark of shoots or stems. Lenticels are natural openings located in the bark of woody plants that allow gaseous exchange, which can be used by some forest pathogens as infection points (Garbelotto 2004, Jung \& Blaschke 2004, Qin \& LeBoldus 2014, Steele et al. 2010). The density of lenticels has been suggested to be associated with infection without wounding to the pathogen Sphaerulina musiva in clones of Populus (Qin \& LeBoldus 2014). This study is focused on elucidating the role of lenticels as potential infection points in ash in the context of ash dieback and presents for the first time, natural infection of lenticels in ash by $H$. fraxineus. The study evaluates lenticel necrosis, shoot dieback, canker-like lesions and bud burst in a provenance trial of almost 4000 ash trees from multiple European provenances, and compares the prevalence of these parameters in crown shoots under conditions of very low disease pressure. Additionally, lenticel density is compared between two groups of ash genotypes with low and high susceptibility to ash dieback. 


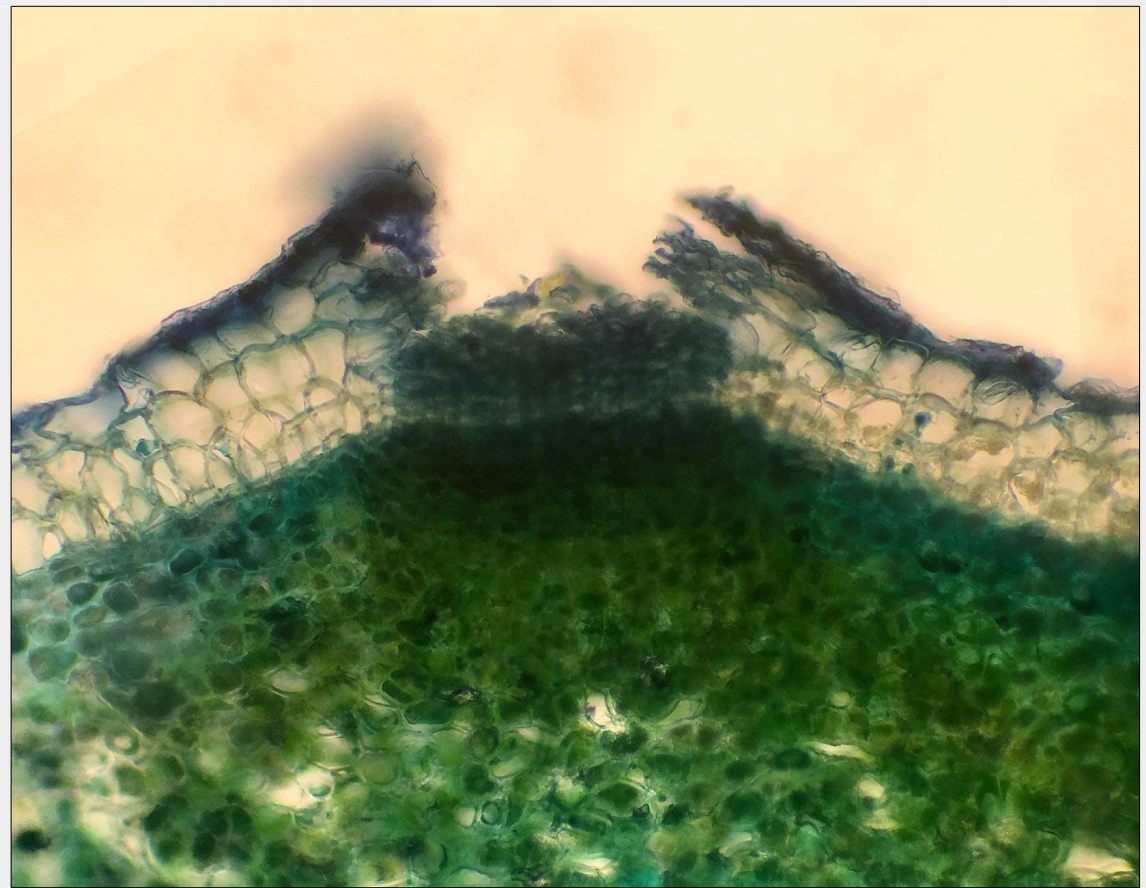

Fig. 1 - Radial section of a lenticel in F. excelsior.

\section{Materials and methods}

\section{Plant material}

For the evaluation of the different symptoms in crown shoots and bud burst, the studied material consisted of eleven yearold $F$. excelsior trees in a European ash provenance trial (RAP) situated in Slatta, Co. Roscommon, in the Republic of Ireland. The trial contained 37 European prove- nances divided into three replicate blocks. Each replicate block had 37 plots, each contained 36 trees from the same provenance. The whole provenance trial was surrounded by 2 rows of ash seedlings from an Irish commercial seed lot. Specific information about the provenance trial design and sampling can be found in Fig. S1 (Supplementary material).

The provenance trial was monitored for
Fig. 2 - Different criteria evaluated in the trees in this study. Canker-like lesions (a), necrotic lenticels (b), shoot dieback

(c) and bud burst in a scale from 1 to 4 (d). a.
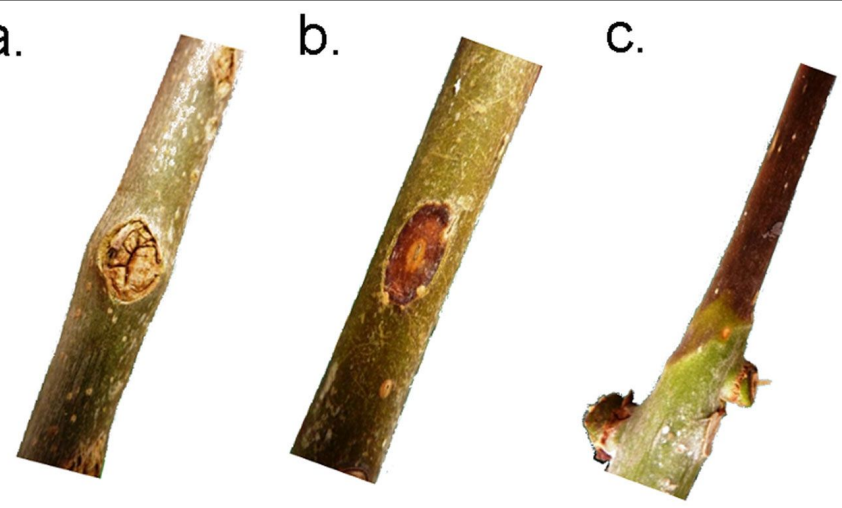

d.
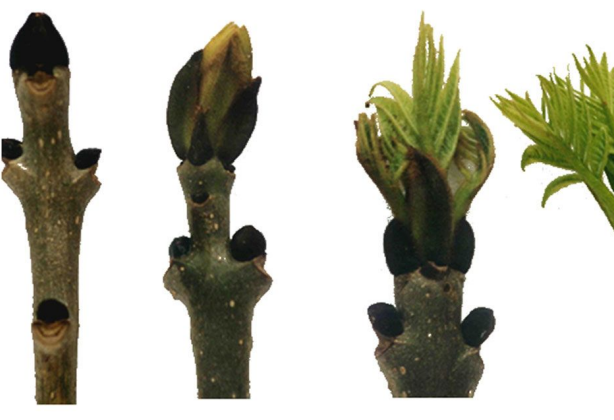

3

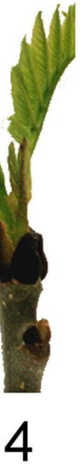

the phenotypic expression of ash dieback disease over the previous period of three years. During that period suspect samples were taken and analyzed by PCR by plant health inspectors in the Irish Department of Agriculture. Ash dieback was absent in that two year period but confirmed as present in the third year of their surveys, which coincided with the year in which samples were taken for fungal isolations in this study. For each tree a branch reaching the canopy level was cut down and shoots were carefully examined and recorded for the presence of shoot dieback and necrotic lenticels. Symptomatic shoots were collected in late May 2017, the first year in which the presence of $H$. fraxineus on the site was confirmed by the Plant Health Regulatory Authority of Ireland. Symptomatic shoots were stored at $4{ }^{\circ} \mathrm{C}$ until further analysis.

Genotypes that showed a high proportion of dieback symptoms in crown shoots in the first year of confirmed infection were categorized as being highly susceptible to ash dieback relative to healthy neighbouring trees. Genotypes categorized as having a low susceptibility to ash dieback were selected within a sister provenance trial in Stevoort, Belgium, in which trees were recorded as having full crowns (and no stem or collar infections), over the previous four years of monitoring in an environment with a high infection pressure and tree mortality. Lenticel density was recorded on stem internodes from ten genotypes with low susceptibility and ten genotypes with high susceptibility to ash dieback. For both cases the internodes were derived from grafted plants. Four to eight shoots from each genotype were grafted at the same time and grown under the same conditions in an unheated glasshouse at Teagasc in Dublin (Ireland) in March 2017. Lenticel numbers were recorded in current-season shoots produced in the glasshouse up to July 2017.

\section{Tree phenotyping}

A total of 3939 trees were examined in the Irish ash provenance trial. For each tree, a branch reaching the canopy level was cut down in early May 2017 and the lenticels examined (Fig. 1). Shoots in the branch were evaluated under four different criteria: the presence or absence of canker-like lesions, the presence or absence of necrotic lenticels, the presence or absence of died-back shoots and bud burst on a scale from 1 to 4 (Fig. 2). All the disease observations were qualitative in nature and no collar lesions were observed. Bud burst observations were quantitative in nature (Scale 1-4).

We compared lenticel densities on current-season shoots produced by grafted plants of ten genotypes of ash with a low susceptibility to $A D B$ and ten genotypes with a high susceptibility to ADB. For each genotype, three shoots on three grafted ramets were analysed. In each of these a 5 
$\mathrm{cm}$ section of the internode was delimited with a fine marker on one-year-old shoots and the number of lenticels was counted. A total of 60 shoots ( 30 low and 30 high susceptibility genotypes) were evaluated and the mean lenticel count was then divided by the surface area of the marked section to compute lenticel density.

\section{Fungal isolation}

Genotypes with infected lenticels were selected randomly within each block of the provenance trial (Fig. S1 in Supplementary material). Shoot samples from 17 of these genotypes were used for fungal isolation. A total of 86 lenticels were dissected and used for fungal isolations. Internodal shoot sections were surface-sterilized by first washing under tap water for 20 minutes followed by immersing them in $2 \% \mathrm{NaOCl}$ for 10 minutes; 30 seconds in $70 \% \mathrm{EtOH}$ followed by two rinses in sterile deionised water. Samples were then allowed to dry in a class 2 biohazard cabinet (ESCO, Portland, OR, USA). The bark was then carefully removed using a sterile scalpel (No. 10 Blade). Small (2-5 $\mathrm{mm}^{2}$ ) pieces of infected plant tissue adjacent to the necrotic lesions were placed on half strength agar amended with $50 \mathrm{mg} \mathrm{l}^{-1}$ streptomycin sulfate. After a period of $1-3$ weeks at $25{ }^{\circ} \mathrm{C}$, isolated fungi were separately subcultured to fresh malt agar, to obtain pure cultures.

\section{DNA extraction and diagnostic of the isolates}

Hyphae were collected in $2 \mathrm{~mL}$ screw cap Eppendorf tubes. Four glass beads were added to the tube and a ball mill (FastPrep $^{\text {TM }}$ FP120, Qbiogene Inc., CA, USA) was used to break the tissue at 4000 vibrations $\min ^{-1}$ for 20 seconds. DNA was extracted using the GenElute ${ }^{\circledast}$ Plant Genomic DNA Miniprep Kit (Sigma-Aldrich, St. Louis, MO, USA) according the manufacturer's instructions. Genomic DNA was eluted in a total volume of $100 \mu \mathrm{L}$ of water.

Internal Transcribed Spacer ITS1 and ITS4 together with the RedTaq $^{\oplus} \mathrm{PCR}$ reaction mix (Sigma-Aldrich) were used for the PCR reactions in a total volume of $50 \mu \mathrm{L}$ using 1 $\mu \mathrm{L}$ of DNA as a template. An initial denaturation step at $94{ }^{\circ} \mathrm{C}$ for 5 minutes was followed by 35 amplification cycles of denaturation at $94{ }^{\circ} \mathrm{C}$ for 15 seconds, annealing at $50{ }^{\circ} \mathrm{C}$ for 30 seconds and extension at $72{ }^{\circ} \mathrm{C}$ for 30 seconds. The thermal cycling was ended by a final extension step at $72^{\circ} \mathrm{C}$ for 7 minutes. PCR products were purified using a GenElute PCR Clean-up kit and purified DNA products were sent to Macrogen (Netherlands) for sequencing. Sequences were compared with the NCBI database using BLAST and genus was annotated for each of the isolates. Complementary morphological identification of the isolates was done in the laboratory using a microscope.

\section{Statistical analyses}

All statistical analyses were carried out with SAS 9.4 software (SAS Inc., Cary, NC,
USA). Phenotypic data were analysed using procedures for linear modelling. Data from individual trees was summarized on a per plot basis before using ANOVA-type analysis to compare means for outcomes and regression analysis to study associations between lenticel infection and other measured characteristics. Simulation techniques were used to adjust for multiplicity effects. Residual plots were checked to ensure that the assumptions of the analyses were met. Log transformation was used to as appropriate to correct skew and nonconstant variance.

The provenance effect on bud burst was modelled using latitude and altitude, along with the block effect. A linear model was fitted with the Mixed procedure.

Lenticel density was compared using a one-way ANOVA analysis comparing the two groups of genotypes with different susceptibility levels to ADB.

\section{Results}

\section{Fungal isolation}

Out of the infected 86 lenticels on which fungal isolation was attempted a total of 39 fungal isolates were successfully isolated and sequenced. Cases where fungal isolation failed were most commonly caused by mould contamination and, in some cases, by the sterilization process, which might have killed the organisms. Species in seven different fungal genera were identified, including Hymenoscyphus fraxineus. The most common genus was Boeremia $(n=23)$, while all other genera ( $D i-$ aporthe, Epicoccum, Didymella, Aspergillus, Neonectria and Hymenoscyphus) were represented by a maximum of five isolates and a minimum of one. Two samples yielded sequences with no known matches in NCBI. The full set of results can be found in Tab. 1.

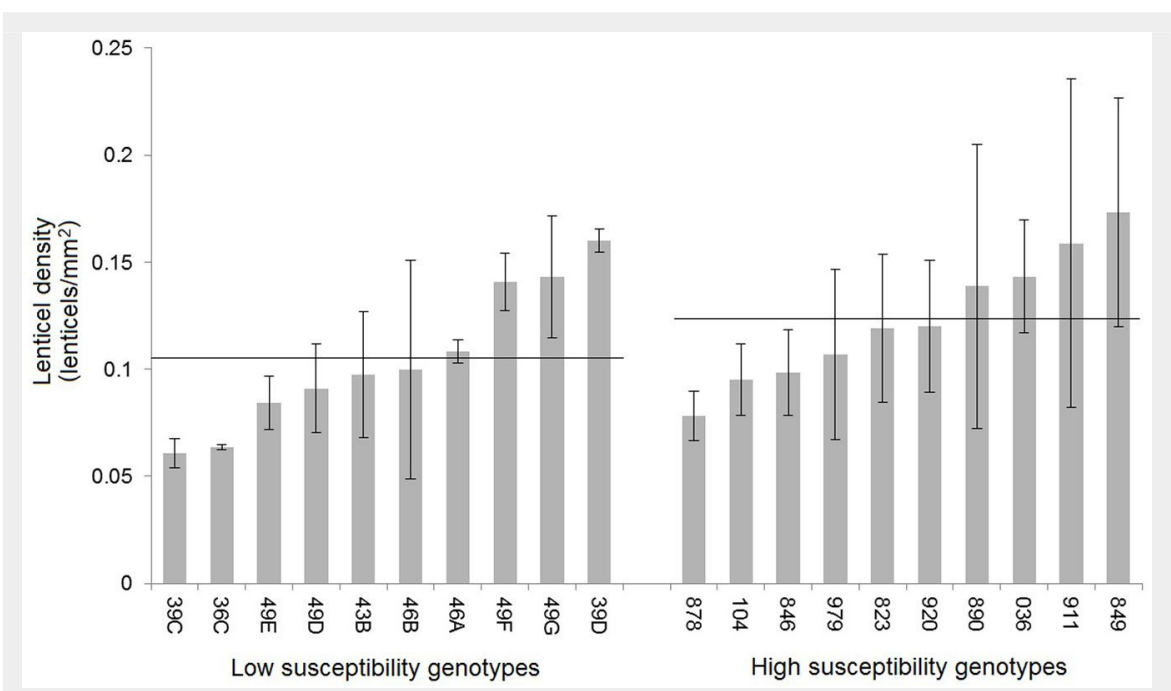

Fig. 3 - Lenticel density (lenticels $\mathrm{mm}^{-2}$ ) for ten low-susceptibility genotypes and ten high-susceptibility genotypes of $F$. excelsior. Error bars represent the standard deviation. Horizontal lines represent the mean lenticel density for each of the two groups of genotypes.
Tab. 1 - The number of the fungal isolates and the identity of the isolates from infected ash lenticels confirmed by ITS sequencing.

\begin{tabular}{lc}
\hline Fungus & $\begin{array}{c}\text { Number of } \\
\text { isolates }\end{array}$ \\
\hline Boeremia spp. & 23 \\
Diaporthe spp. & 5 \\
Epicoccum nigrum & 4 \\
(Unknown fungus) & 2 \\
Aspergillus spp. & 2 \\
Hymenoscyphus fraxineus & 1 \\
Neonectria ditissima & 1 \\
Didymella spp. & 1 \\
\hline
\end{tabular}

\section{Lenticel density}

Lenticel density showed significant differences among genotypes $(\mathrm{p}=0.0019)$, ranging from $0.06 \pm 0.01$ to $0.17 \pm 0.03$ lenticels $\mathrm{mm}^{-2}$ (Fig. 3). Even though the average lenticel density was slightly lower for genotypes with low susceptibility, as shown in Fig. 3, the difference between these and the highly susceptible group was not statistically significant.

\section{Statistical analyses of tree phenotypes}

Bud burst was annotated for 3939 trees with an average bud burst of 2.62 in the scale from 1 to 4 , showing that the time of the spring when the trees were surveyed was appropriate. For the other three criteria: shoot dieback, canker-like lesions and necrotic lenticel lesions, fewer trees were surveyed (3890), as some of the trees in the field were too small to be accurately evaluated due to provenance effects. Lenticel necrosis was observed in 1099 trees (28.25\%), canker-like lesions were observed in 1216 trees (31\%) and shoot dieback was observed in 1576 trees (40.05\%). Additional 


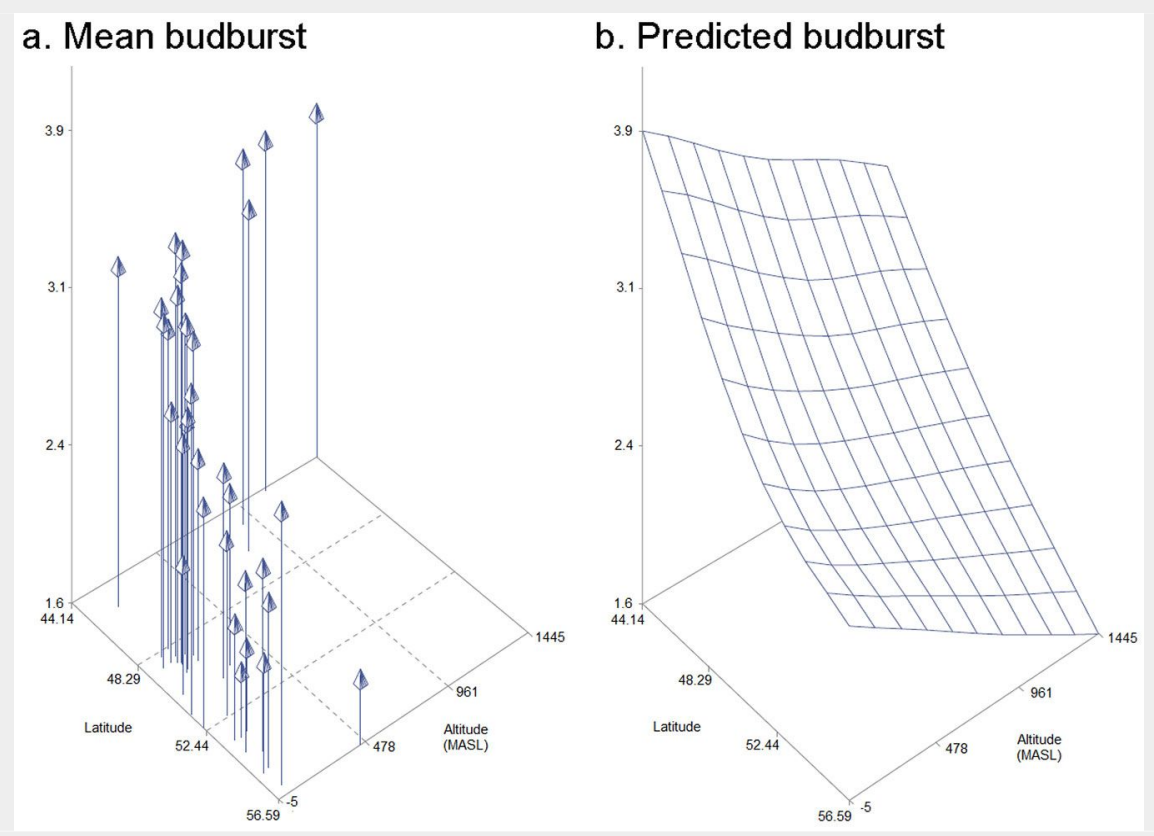

Fig. 4 - Model representing mean bud burst, latitude and altitude for each of the 37 provenances of $F$. excelsior that were studied in the Irish provenance trial (a.) and predicted values for bud burst for a given altitude and latitude (b.).

information on the distribution of these symptoms within the provenance trial can be found in Fig. S2 (Supplementary material).

Statistical analyses revealed a block effect for canker-like lesion ( $p=0.0024)$, lenticel necrosis $(p=0.0032)$, shoot dieback $(p<0.0001)$ and bud burst $(p<0.0001)$. Block effects were included in the statistical models. Provenance effects were not ob served for shoot dieback, lenticel necrosis or canker-like lesions. On the other hand, bud burst was affected very significantly by provenance $(p<0.0001)$. A 3D model includ ing latitude, altitude and bud burst was created to show how these variables corre late (Fig. 4). Specific information on each of the provenances can be found in Tab. S1 (Supplementary material). Bud burst did not show a correlation with any of the other three symptoms that were evalu ated. The strongest correlation was observed between lenticel necrosis and canker-like lesion $(r=0.81)$. A weaker correlation was observed between shoot dieback and canker-like lesion $(r=0.45)$ and shoot dieback and lenticel necrosis $(r=0.41)$.

\section{Discussion}

This study is the first attempt to identify the range of fungal organisms that can use lenticels as entry points to infect $F$. excelsior shoots. Several forest pathogens in different genera were isolated from infected lenticels in this study. Most of them have been already described in previous studies concerning microbial diversity in ash (Griffith \& Boddy 1988, Kowalski et al. 2016, Kosawang et al. 2018). However, this is the first study in which $\mathrm{H}$. fraxineus was isolated from necrotic lenticel tissue. Previous work in ash dieback refers to lenticel infec tions as "necrotic shoot bark" and "small bark wounds" on ash shoots (Bakys et al. 2009) or "lesions" (Kowalski \& Holdenrieder 2009). These observations may have resulted from lenticel infections but were unrecognized.

Lenticel infection is a well-known infection mechanism in other forest pathosystems such as in Quercus (Garbelotto 2004), Alnus (Jung \& Blaschke 2004), Aesculus (Laue et al. 2014) and Populus (Qin \& LeBoldus 2014) and we confirmed the susceptibility of ash lenticels to a range of fungi. In our study a single isolate out of 39 was confirmed to be $H$. fraxineus. Low frequency of H. fraxineus among the isolates could be explained by the relatively low disease pressure on the site, which was just going through the first year of dieback infection. Another explanation is that malt agar was used while specific media types such as ADA (Botella et al. 2016) might have been more favourable for $\mathrm{H}$. fraxineus. It is also possible that some of the native fungi that were found in this study may have a higher abundance and capacity to infect ash lenticels, having coexisted with their host for a longer time, which would render $\mathrm{H}$. fraxineus as a minor competing pathogen of ash lenticels. Finally, there is the possibility that $H$. fraxineus initially infected a higher proportion of the lenticels but was later outcompeted by other organisms, as it often happens during the isolation of this pathogen from infected plant material. This possibility would be in line with the hypothesis that $H$. fraxineus facilitates the infection by other forest pathogens such as Armillaria spp., as suggested by Husson et al. (2012). The most common among the isolates were those belonging to the genus Boeremia, also known as Phoma. This is a very common minor pathogen that has been reported previously in the context of ash dieback (Bakys et al. 2009, Kowalski et al. 2017, Kowalski et al. 2016, Schlegel et al. 2016) and fits the profile of an opportunistic pathogen causing minor damage to the host.

Stem collar infections at ground level are a major cause of tree mortality and a major concern at later stages of the ash dieback disease when disease pressure is very high (Chandelier et al. 2016, Muñoz et al. 2016, Enderle et al. 2017b). Collar infections were not found in the present study and this is consistent with observations that collar infections have never been reported during the first year of infection. However, the present study has confirmed that lenticels are vulnerable to infection by $\mathrm{H}$. fraxineus even in a low disease pressure environment in crown shoots, where we assume that conditions favouring the infection of lenticels in crown shoots would be even more demanding than for leaf laminas, i.e., smaller surface areas for spore contact and the corky cell types. Consequently, the isolation of $\mathrm{H}$. fraxineus from necrotic lenticel tissue in the crown shoots was unexpected. Stem lenticels have been hypothesized as the main entry points and initial cause of collar necrosis, leading to tree mortality (Enderle et al. 2013, Chandelier et al. 2016). We find this is a reasonable hypothesis, especially because of the high density of ascocarps at ground level (Havrdová et al. 2017) resulting in highest concentration of spores near the base of the trees (Chandelier et al. 2014) and together with favourable humidity and temperature conditions (Marcais et al. 2016). Furthermore, the presence of moisture-holding mosses at the tree collars, and the potential for the accumulation of spores which would be washed downwards in water films from tree surfaces. The findings in the present study support the hypothesis of lenticel infection in ash. However, a more detailed study demonstrating the early stages of necrosis in tree collars is required for confirmation.

Lenticel density showed a significant variation among ash genotypes. Even though average lenticel density was lower for the low susceptibility group of genotypes, this difference was not significant. Physiological and morphological changes in lenticels have been shown to be important in poplar trees where lenticels are major infection points (Qin \& LeBoldus 2014). Lenticels and leaf scars are the main infection points for Neonectria spp., which cause canker in apple and other tree species (Flack \& Swinburne 1977). In ash, however, literature has often considered bark wounds and openings to be the entry point for fungal and bacterial cankers (Flack \& Swinburne 1977, Janse 1981, Janse 1982) but lenticels have never been considered in this context. Our work shows that many known pathogens can use lenticels as entry points to infect ash shoot bark. The morphology of ash 
lenticels is known to vary depending on different environmental factors such as flooding (Tang \& Kozlowski 1984, Yamamoto et al. 1995). A study focused on the interaction between European horse chestnut and Pseudomonas syringae showed that lenticels are more likely to be infected in spring and summer, while in the autumn, morphological changes in their structure make them more resilient to infection (Laue et al. 2014). Our results show a strong correlation between canker-like infection in shoots and lenticel necrosis, suggesting that lenticels are vulnerable and can host different types of organisms, depending on their physiology and other characteristics. Further studies focusing on the characteristics of ash lenticels are needed to understand how they might affect infection. In contrast to previous studies (Skovsgaard et al. 2010) we observed a weak correlation of shoot dieback with canker-like lesions and lenticel necrosis. This suggests that trees that present lenticel infections are more likely to also show shoot dieback or, perhaps, that some of the observed shoot dieback was initiated and caused by lenticel infections.

We found no correlation between bud burst and any of the other three symptomatic traits. Some authors (McKinney et al. 2012, 2014, Bakys et al. 2013, Hietala et al. 2013, Nielsen et al. 2017b) have suggested that bud burst and leaf senescence have an effect on the susceptibility of individual genotypes to ash dieback. The population in this study included trees with a very broad genetic base and significantly different bud burst values but shoot dieback was not correlated with provenance source. In the present study, the absence of a provenance effect in the incidence of shoot dieback is consistent with the findings from other studies where minor provenance effects in susceptibility to ash dieback were detected (Pliura et al. 2011, Enderle et al. 2013, Havrdová et al. 2016).

\section{Conclusions}

As in other forest tree species, lenticels are a natural entry point for fungal pathogens in $F$. excelsior. $H$. fraxineus was isolated from infected ash lenticels in a forest with low ash dieback disease pressure. Lenticel density is not significantly different between genotypes with different susceptibility levels to ash dieback. Lenticel necrosis is highly correlated with cankerlike lesions in ash. Both these traits show a weak correlation with shoot dieback.

\section{Acknowledgments}

MNG and GD conceived and designed the experiments; MNG, GD and LD collected the samples and evaluated the different traits on the trees. BM performed the fungal isolations and the microscopic characterization of the isolates. BM, MNG and LD isolated and tested the DNA for the isolates. JG did the statistical analysis of the data. MNG and GD wrote the manuscript with the help of the rest of the authors.

The authors acknowledge the financial support of the Irish Department of Agriculture Food and Marine for this FORM project and the generosity of Dr. M. Steenackers (INBO, Belgium), for providing shoots of ash genotypes with low susceptibility to ash dieback for propagation by grafting.

\section{References}

Bakys R, Vasaitis R, Barklund P, Ihrmark K, Stenlid J (2009). Investigations concerning the role of Chalara fraxinea in declining Fraxinus excelsior. Plant Pathology 58 (2): 284-292. - doi: 10.1016/j.funbio.2017.11.002

Bakys R, Vasaitis R, Skovsgaard JP (2013). Patterns and severity of crown dieback in young even-aged stands of European ash (Fraxinus excelsior L.) in relation to stand density, bud flushing phenotype, and season. Plant Protection Science 49 (3): 120-126. - doi: 10.17221/70/20 12-PPS

Baral HO, Queloz V, Hosoya T (2014). Hymenoscyphus fraxineus, the correct scientific name for the fungus causing ash dieback in Europe. IMA Fungus 5 (1): 79-80. - doi: 10.5598/imafungus.20 14.05.01.09

Botella L, Cermáková V, Bačová A, Dvorák $M$ (2016). ADA, a fast-growth medium for Hymenoscyphus fraxineus. Forest Pathology 46 (1): 85 87. - doi: 10.1111/efp.12251

Chandelier A, Helson M, Dvorak M, Gischer F (2014). Detection and quantification of airborne inoculum of Hymenoscyphus pseudoalbidus using real-time PCR assays. Plant Pathology 63 (6): 1296-1305. - doi: 10.1111/ppa.12218

Chandelier A, Gerarts F, San Martin G, Herman $M$, Delahaye L (2016). Temporal evolution of collar lesions associated with ash dieback and the occurrence of Armillaria in Belgian forests. Forest Pathology 46 (4): 289-297. - doi: 10.1111/ efp. 12258

Enderle R, Peters F, Nakou A, Metzler B (2013). Temporal development of ash dieback symptoms and spatial distribution of collar rots in a provenance trial of Fraxinus excelsior. European Journal of Forest Research 132 (5-6): 865-876. doi: 10.1007/s10342-013-0717-y

Enderle R, Sander F, Metzler B (2017a). Temporal development of collar necroses and butt rot in association with ash dieback. iForest - Biogeosciences and Forestry 10: 529-536. - doi: 10.383 2/ifor2407-010

Enderle R, Busskamp J, Metzler B (2017b). Growth performance of dense natural regeneration of Fraxinus excelsior under attack of the ash dieback agent Hymenoscyphus fraxineus. Baltic Forestry 23 (1): 218-228. [online] URL: http://www.researchgate.net/publication/31727 8737

Flack NJ, Swinburne TR (1977). Host range of Nectria galligena Bres. and the pathogenicity of some Northern Ireland isolates. Transactions of the British Mycological Society 68 (2): 185-192. doi: 10.1016/S0007-1536(77)80007-7

Garbelotto M (2004). Sudden oak death: a tale of two continents. Outlooks on pest management 15 (2): 85. - doi: 10.1564/15apl12

Griffith GS, Boddy L (1988). Fungal communities in attached ash (Fraxinus excelsior) twigs. Transactions of the British Mycological Society
91: 599-606. - doi: 10.1016/S0007-1536(88)8003 3-0

Gross A, Holdenrieder O, Pautasso M, Queloz V, Sieber TN (2014). Hymenoscyphus pseudoalbidus, the causal agent of European ash dieback. Molecular Plant Pathology 15 (1): 5-21. - doi: 10.1111/mpp.12073

Hauptman T, Ogris N, Groot M, Piškur B, Jurc D (2016). Individual resistance of Fraxinus angustifolia clones to ash dieback. Forest Pathology 46 (4): 269-280. - doi: 10.1111/efp.12253

Havrdová L, Novotná K, Zahradník D, Buriánek V, Pešková V, Srutka P, Cerny K (2016). Differences in susceptibility to ash dieback in Czech provenances of Fraxinus excelsior. Forest Pathology 46 (4): 281-288. - doi: 10.1111/efp.12265

Havrdová L, Zahradník D, Romportl D, Pešková V, Cerny K (2017). Environmental and silvicultural characteristics influencing the extent of ash dieback in forest stands. Baltic Forestry 23 (1): 168-182. [online] URL: http://www.research gate.net/publication/317000052

Hietala AM, Timmermann V, Borja I, Solheim H (2013). The invasive ash dieback pathogen $\mathrm{Hy}$ menoscyphus pseudoalbidus exerts maximal infection pressure prior to the onset of host leaf senescence. Fungal Ecology 6 (4): 302-308. doi: 10.1016/j.funeco.2013.03.008

Husson C, Cael O, Grandjean JP, Nageleisen LM, Marcais B (2012). Occurrence of Hymenoscyphus pseudoalbidus on infected ash logs. Plant Pathology 61 (5): 889-895. - doi: 10.1111/j.13653059.2011.02578.x

Janse J (1981). The bacterial disease of ash (Fraxinus excelsior), caused by Pseudomonas syringae subsp. savastanoi pv. fraxini. Forest Pathology, 11 (5-6), 306-315. - doi: 10.1111/j.1439-03 29.1981.tboo115.x

Janse J (1982). Pseudomonas syringae subsp. savastanoi (ex Smith) subsp. nov., nom. rev., the bacterium causing excrescences on Oleaceae and Nerium oleander L. International Journal of Systematic and Evolutionary Microbiology 32 (2): 166-169. - doi: 10.1111/j.1439-0329.1982.tbo14 72.x

Jung T, Blaschke M (2004). Phytophthora root and collar rot of alders in Bavaria: distribution, modes of spread and possible management strategies. Plant Pathology 53 (2): 197-208. doi: 10.1111/j.0032-0862.2004.00957.x

Kirisits T, Matlakova M, Mottinger-Kroupa S, Halmschlager E, Lakatos F (2010). Chalara fraxinea associated with dieback of narrow-leafed ash (Fraxinus angustifolia). Plant Pathology 59 (2): 411-411. - doi: 10.1111/j.1365-3059.2009.0216 2.x

Kosawang C, Amby DB, Bussaban B, McKinney LV, Xu J, Kjr ED, Collinge DB, Nielsen LR (2018). Fungal communities associated with species of Fraxinus tolerant to ash dieback, and their potential for biological control. Fungal Biology 122 (2-3): 110-120. - doi: 10.1016/j.funbio.2017.11.002 Kowalski T (2001). O zamieraniu jesionów [Dieback of ash]. Trybuna Lesnika 4 (359): 6-7. [in Polish]

Kowalski T (2006). Chalara fraxinea sp. nov. associated with dieback of ash (Fraxinus excelsior) in Poland. Forest Pathology 36 (4): 264-270. doi: 10.1111/j.1439-0329.2006.00453.x

Kowalski T, Holdenrieder O (2009). Pathogenicity of Chalara fraxinea. Forest Pathology 39 (1): 
1-7. - doi: 10.1111/j.1439-0329.2008.00565.x Kowalski T, Bartnik C (2010). Morphologial variation in colonies of Chalara fraxinea isolated from ash (Fraxinus excelsior L.) stems with symptoms of dieback and effects of temperature on colony growth and structure. Acta Agrobotanica 63 (1): 99-106. - doi: 10.5586/aa.20 10.012

Kowalski T, Kraj W, Bednarz B (2016). Fungi on stems and twigs in initial and advanced stages of dieback of European ash (Fraxinus excelsior) in Poland. European Journal of Forest Research 135 (3): 565-579. - doi: 10.1007/s10342-016-0955$\mathrm{x}$

Kowalski T, Bilanski P, Kraj W (2017). Pathogenicity of fungi associated with ash dieback towards Fraxinus excelsior. Plant Pathology 66 (8): 1228-1238. - doi: 10.1111/ppa.12667

Kräutler K, Treitler R, Kirisits T (2015). Hymenoscyphus fraxineus can directly infect intact current-year shoots of Fraxinus excelsior and artificially exposed leaf scars. Forest Pathology 45 (4): 274-280. - doi: 10.5586/aa.2010.012

Laue BE, Steele H, Green S (2014). Survival, cold tolerance and seasonality of infection of European horse chestnut (Aesculus hippocastanum) by Pseudomonas syringae pv. aesculi. Plant Pathology 63 (6): 1417-1425. - doi: 10.1111/ppa.122 13

Marcais B, Husson C, Godart L, Cael O (2016). Influence of site and stand factors on Hymenoscyphus fraxineus-induced basal lesions. Plant Pathology 65 (9): 1452-1461. - doi: 10.1111/ppa.1 2542

McKinney LV, Thomsen IM, Kjaer ED, Nielsen LR (2012). Genetic resistance to Hymenoscyphus pseudoalbidus limits fungal growth and symptom occurrence in Fraxinus excelsior. Forest Pathology 42 (1): 69-74. - doi: 10.1111/j.14390329.2011.00725.X

McKinney LV, Nielsen LR, Collinge DB, Thomsen IM, Hansen JK, Kjaer ED (2014). The ash dieback crisis: genetic variation in resistance can prove a long-term solution. Plant Pathology 63 (3): 485-499. - doi: 10.1111/ppa.12196

McMullan M, Rafiqi M, Kaithakottil G, Clavijo BJ, Bilham L, Orton E, Percival-Alwyn L, Ward BJ,
Edwards A, Saunders DG, Accinelli GG (2018). The ash dieback invasion of Europe was founded by two genetically divergent individuals. Nature Ecology and Evolution 2 (6): 1000. doi: 10.1038/s41559-018-0548-9

Muñoz F, Marçais B, Dufour J, Dowkiw A (2016). Rising out of the ashes: additive genetic variation for crown and collar resistance to Hymenoscyphus fraxineus in Fraxinus excelsior. Phytopathology 106 (12): 1535-1543. - doi: 10.1094/PHY TO-11-15-0284-R

Nielsen LR, McKinney LV, Hietala AM, Kjaer ED (2017a). The susceptibility of Asian, European and North American Fraxinus species to the ash dieback pathogen Hymenoscyphus fraxineus reflects their phylogenetic history. European Journal of Forest Research 136 (1): 59-73. - doi: 10.1007/s10342-016-1009-0

Nielsen LR, Mckinney LV, Kjaer ED (2017b). Host phenological stage potentially affects dieback severity after Hymenoscyphus fraxineus infection in Fraxinus excelsior seedlings. Baltic Forestry 23 (1): 229-232.

Pliura A, Lygis V, Suchockas V, Bartkevicius E (2011). Performance of twenty four European Fraxinus excelsior populations in three Lithuanian progeny trials with a special emphasis on resistance to Chalara fraxinea. Baltic Forestry 17 (1): 17-34. [online] URL: http://www.research gate.net/publication/262599916

Qin RQ, LeBoldus JM (2014). The infection biology of Sphaerulina musiva: clues to understanding a forest pathogen. PLoS ONE 9 (7): e1034 77. - doi: 10.1371/journal.pone.0103477

Schlegel M, Dubach V, Von Buol L, Sieber TN (2016). Effects of endophytic fungi on the ash dieback pathogen. FEMS Microbiology Ecology 92 (9): fiw142. - doi: 10.1093/femsec/fiw142

Schumacher J, Kehr R, Leonhard S (2010). Mycological and histological investigations of Fraxinus excelsior nursery saplings naturally infected by Chalara fraxinea. Forest Pathology 40 (5): 419-429. - doi: 10.1111/j.1439-0329.2009.00615.x Schwanda K, Kirisits T (2016). Pathogenicity of Hymenoscyphus fraxineus towards leaves of three European ash species: Fraxinus excelsior, F. angustifolia and F. ornus. Plant Pathology 65
(7): 1071-1083. - doi: 10.1111/ppa.12499

Skovsgaard JP, Thomsen IM, Skovgaard I, Martinussen T (2010). Associations among symptoms of dieback in even-aged stands of ash (Fraxinus excelsior L.). Forest Pathology 40 (1): 7-18. - doi: 10.1111/j.1439-0329.2009.00599.x Sønstebø JH, Vivian-Smith A, Adamson K, Drenkhan R, Solheim H, Hietala A (2017). Genomewide population diversity in Hymenoscyphus fraxineus points to an eastern Russian origin of European Ash dieback. bioRxiv: 154492. - doi: 10.1101/154492

Steele H, Laue BE, MacAskill GA, Hendry SJ, Green S (2010). Analysis of the natural infection of European horse chestnut (Aesculus hippocastanum) by Pseudomonas syringae pv. aesculi. Plant Pathology 59 (6): 1005-1013. - doi: 10.1111/j.1365-3059.2010.02354.x

Tang ZC, Kozlowski TT (1984). Water relations, ethylene production, and morphological adaptation of Fraxinus pennsylvanica seedlings to flooding. Plant and Soil 77 (2-3): 183-192. - doi: 10.1007/BF02182922

Yamamoto F, Sakata T, Terazawa K (1995). Physiological, morphological and anatomical responses of Fraxinus mandshurica seedlings to flooding. Tree Physiology 15 (11): 713-719. - doi: 10.1093/treephys/15.11.713

\section{Supplementary Material}

Fig. S1 - Information about the RAP trial in Slatta, Co. Roscommon (Ireland), 53.79 N, $7.98 \mathrm{~W}$.

Fig. S2 - Scoring for each tree in the RAP trial in Roosky for the presence (red) or absence (green) of lenticel necrosis, shoot dieback and canker lesion.

Tab. S1 - Geographic information and mean budburst values for each of the 37 provenances in the study and statistical categories after the ANOVA analysis.

Link: Nemesio-Gorriz_2897@supplo01.pdf 